HARRAN ÜNIVERSITESI MÜHENDISLIK FAKÜLTES

HARRAN

ÜNIVERSITESI

MÜHENDISLIK DERGisi

HARRAN UNIVERSITY

JOURNAL OF ENGINEERING

e-ISSN: 2528-8733

\section{HARRAN ÜNIVERSITESİ MÜHENDİSLİK DERGISII}

HARRAN UNIVERSITY JOURNAL of ENGINEERING

e-ISSN: 2528-8733 (ONLINE)

URL: http://dergipark.gov.tr/humder

Açık Kaynak Kodlu Yazılımlarla Web Tabanlı Mobil Mekânsal Veri Toplama Arayüzü Geliştirilmesi

Development of Web-Based Mobile Spatial Data Collection Interface with Open Source Software

Yazar(lar) (Author(s)): Halil İbrahim ONYIL'1, Mustafa ULUKAVAK²

1 ORCID ID: 0000-0002-7916-8820

2 ORCID ID: 0000-0003-2092-3075

Bu makaleye şu şekilde atıfta bulunabilirsiniz (To cite to this article): Onyll.H.İ., Ulukavak M., "Açık Kaynak Kodlu Yazılımlarla Web Tabanlı Mobil Mekânsal Veri Toplama Arayüzü Geliştirilmesi", Harran Üniversitesi Mühendislik Dergisi, 6(2): 111-120, (2021).

Erişim linki (To link to this article): http://dergipark.gov.tr/humder/archive 


Mühendislik Dergisi

Araștırma Makalesi

\title{
Açık Kaynak Kodlu Yazılımlarla Web Tabanlı Mobil Mekânsal Veri Toplama Arayüzü Geliştirilmesi
}

\author{
Halil İbrahim ONYIL ${ }^{1, *}$ Mustafa ULUKAVAK ${ }^{1}$ \\ ${ }^{1}$ Harran Üniversitesi, Mühendislik Fakültesi, Harita Mühendisliği Bölümü, 63100, Haliliye/ŞANLIURFA
}

\begin{abstract}
Öz
Makale Bilgisi

Başvuru: 08/03/2021

Yayın: $31 / 08 / 2021$

Anahtar Kelimeler

Açık kaynak yazılım,

$C B S$,

Web,

Mobil,

Mekânsal Veri toplama,

Coğrafi Bilgi Sistemleri (CBS) beş temel bileşenden oluşmaktadır. Bunlar; veri, yöntem, personel, yazılım ve donanımdır. Veri; toplanması, değerlendirilmesi ve analizi yönüyle projelerin en fazla bütçe ayrılan kısmını oluşturmaktadır. Mekânsal verilerin doğru, hassas ve zamanında toplanması, mühendislik projeleri ve bilimsel çalışmaların sürdürülebilirliği açısından önem arz etmektedir. Bu çalışma kapsamında, günümüzde yaygın kullanıma sahip olan mobil cihazlar aracılığıyla; kolay, erişilebilir ve eş zamanlı kullanılabilen bir kullanıcı arayüze sahip web tabanlı bir mobil platform geliştirilmiştir. Sonuç olarak geliştirilen platformun; farklı üç mobil cihazdan (e-Survey GNSS el terminali, Samsung tablet, Huawei mobil cep telefonu) oluşan bir performans değerlendirmesi gerçekleştirilmiştir. Mobil cihazların anlık olarak erişebildiği, veri tabanına veri girişi sağladığı sistemin, zamandan ve mekândan bağımsız bir şekilde çalıştığı gözlemlenmiştir. Ayrıca bilgisayar ortamında, girilen verilerin anlık olarak veri tabanından çekilerek, masaüstü CBS yazılımı ile de değerlendirme ve analiz imkânı test edilmiştir.

\section{Development of Web-Based Mobile Spatial Data Collection Interface with Open Source Software}

\section{Keywords}

Open source software,

GIS,

Web,

Mobile,

Spatial data collection,

\begin{abstract}
Geographic Information Systems (GIS) consists of five basic components. These; data, method, personnel, software and hardware. Data; It constitutes the most budgeted part of the projects in terms of collection, evaluation and analysis. Accurate, precise and timely collection of spatial data is important for the sustainability of engineering projects and scientific studies. Within the scope of this study, via mobile devices that are widely used today; A web-based mobile platform has been developed with an easy, accessible and simultaneously usable user interface. As a result of the developed platform; a performance evaluation was carried out consisting of 3 different mobile devices (e-Survey GNSS handheld terminal, Samsung tablet, LG mobile phone). It has been observed that the system, which can be accessed instantly by mobile devices and provides data entry to the database, operates independently from time and place. In addition, the data entered in the computer environment was instantly extracted from the database and the evaluation and analysis possibility was tested with desktop GIS software.
\end{abstract}

\section{GİRIŞ (INTRODUCTION)}

Açık kaynak kodlu yazılımlar her geçen gün dünya ülkeleri tarafindan tercih edilmektedir. Lisans ve ücret sorunu yaratmayan bu yazılımlar, sahip olduğu kamu lisansı, kolay erişilebilir ve kullanışlı olması yönüyle Peru, İsrail, İspanya ve Almanya gibi ülkeler tarafindan öncelikli olarak tercih edilmektedir [1]. TODO Group tarafından 2018 yılında şirketler üzerinde gerçekleştirilen bir araştırmaya göre; finans, telekomünikasyon ve haberleşme, yazılım ve IT firmaları tarafindan tercih edilme oranlarını gösteren sonuç grafiği Şekil 1'de gösterilmektedir [2]. 


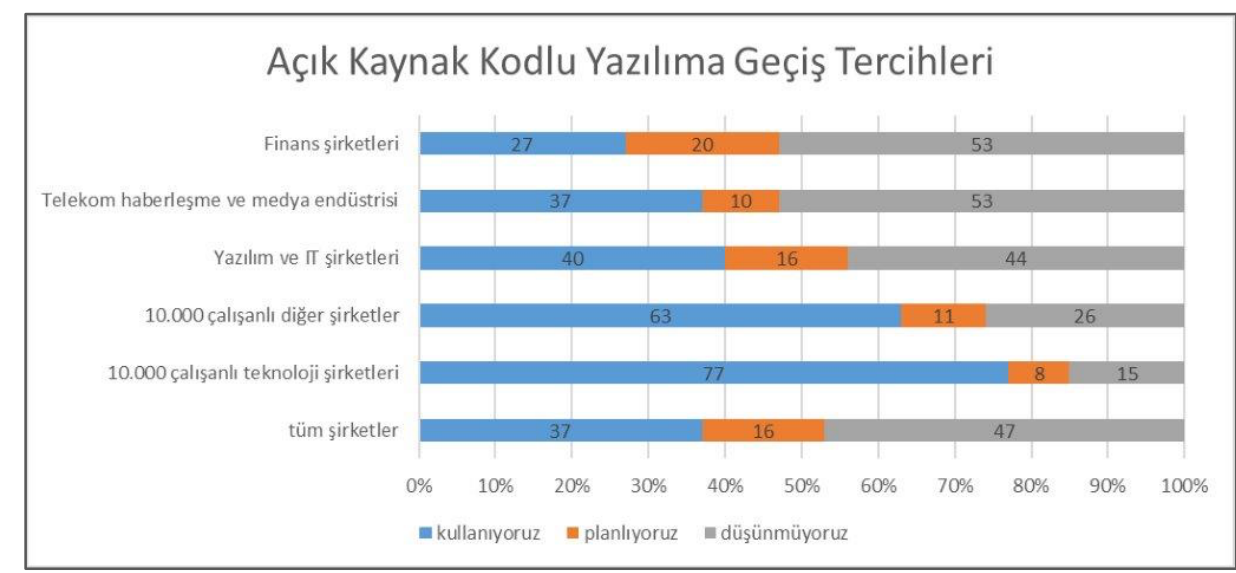

Şekil 1. TODO Grup açık kaynak kodlu yazılıma geçiş tercihleri (TODO Group, 2018)

Şekil 1'e göre, finans şirketlerinin; \%27'si, telekomünikasyon şirketlerinin \%37'si, yazılım firmalarının \%40'1 açık kaynak kodlu yazılıma geçtiklerini ifade etmektedir. Toplamda şirketlerin, \%37'si açık kaynak kod yazılım kullanmaya devam etmektedir. Diğer taraftan; finans şirketlerinin \%20'si, telekomünikasyon şirketlerinin \%10'u, yazılım firmalarının \%16'sı, açık kaynak kodlu yazılıma geçmeyi planladıklarını ifade ederek, toplamda,\%16 gibi anlamlı bir değer ortaya koymaktadır. Şirket personel sayısının 10 bin olduğu teknoloji şirketleri ise \%77' lik oranla açık kaynak kodlu yazılım kullandıklarını teyit etmiştir.

Bir diğer araştırma ise, Şekil 2'de DB-Engines Ranking tarafından Mart 2021 tarihinde listelemiş olunan, veri tabanlarını ve açık kaynak kodlu veri tabanlarının grafiği göstermektedir [3].

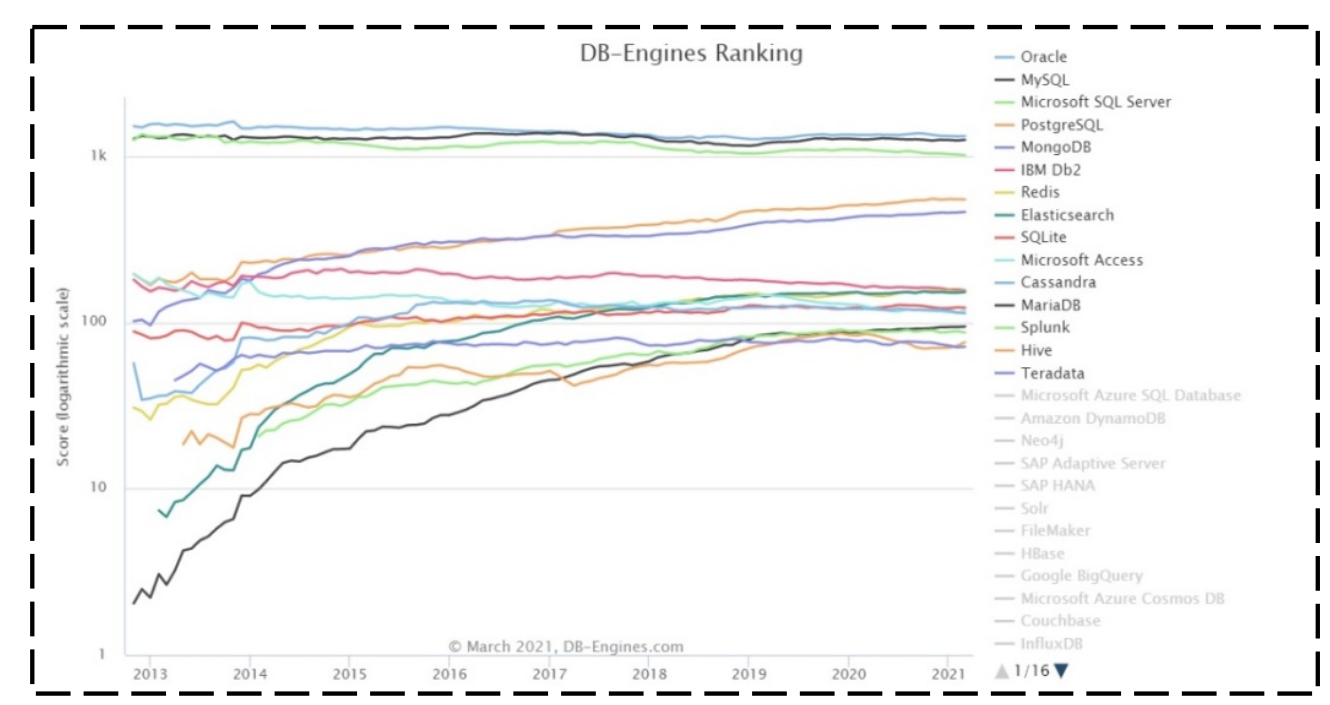

Şekil 2. DB-Engines Ranking veritabanlarl ve açık kaynak kodlu veritabanlarl grafiği (DB-Engines Ranking, 2021)

Şekil 2'ye göre; dünya üzerinde kullanılan, veri tabanları ve açık kaynak kodlu veri tabanlarının kullanımının 2013 y1lından, 2021 yılına kadar olan kullanım trendi gösterilmektedir. Grafiğe göre; PostgreSQL, MySQL veri tabanlarının her geçen yıl artışla, kullanımının arttığı gözlemlenmektedir. Diğer taraftan kapalı kaynak-ücretli veri tabanı olan Microsoft Access, Microsoft SQL Server'ın azalma eğilimi gösterdiği gözlemlenmektedir.

Günümüze kadar literatürde gerçekleştirilen birçok CBS çalışmasında, açık kaynak kodlu CBS yazılımlarının kullanıldığını görmekteyiz $[4,1,5,6,7,8,9]$.

Bu çalışmalardan, Yalçın ve Sabah [10], tarafından, Edirne İlinde bulunan sanayi bölgelerinin deprem riskinin tespitine yönelik yaptığı çalışmada açık kaynak kodlu yazılımlar ve analitik hiyerarşi proses (AHP) yöntemi kullanmasıdır. Çalışma kapsamında, bölgeye ilişkin aktif fay hatları, sanayi kuruluşları, 
il/ilçe sınır bilgileri, meydana gelen deprem faaliyetlerini bir arada değerlendirilerek, sanayi kuruluşlarının deprem risk yoğunluğu tespit edilmiştir. Sonuç olarak Enez ve Keşan ilçelerinde bulunan sanayi kuruluşları deprem riski yönüyle yüksek tehlikeli yoğunluğa sahip olduğu ortaya koyulmuştur. Bir diğer çalışma ise, Apaydın ve Abdikan [11], tarafından gerçekleştirilen, findık alanlarının uydu görüntüleri ile piksel tabanlı sınıflandırılması çalışmasıdır. Çalışmada, QGIS açık kaynak kodlu CBS yazılımı kullanılmıştır. Yazılım içerisinde üç farklı makine öğrenme algoritması (rastgele orman (RO), K en yakın komşu (K-EYK) ve destek vektör makineleri (DVM)) kullanılmıştır.

Günümüz dünyasında, internet kullanımının arttığını gösteren, We Are Social ve Hootside tarafindan yapılan bir araştırmaya göre, 2020 yılı küresel internet kullanımı miktarı, dünya nüfusunun \%59 ile 4.54 milyar kişidir [12]. İnternet kullanımının artmasına bağlı olarak, mobil cihazlara olan rağbette artmıştır [13]. Aynı araştırmada, mobil cihazlardan internet kullanımının ise, 5.19 milyar ile dünya nüfusunun \%67'sine karş1lık etmektedir.

Birçok bilimsel çalışmada olduğu gibi CBS alanında da çalışmalar her geçen gün, web ortamına, oradan da mobil cihazlara ve el terminallerine taşınmaktadır. Bu alanda yapılan çalışmalar bulunmaktadır [14, $15,10,16]$.

Çağatay ve Yıldız [17], tarafından gerçekleştirilen çalışmada, belediyeler tarafından çevre yönetiminin açık kaynak kodlu CBS yazılımları ile yönetilmesini içeren web tabanlı bir kent bilgi sistemi çalışması buna örnektir. Çalışma kapsamında, İstanbul ve İzmir kentleri pilot kentler seçilerek. Kente ilişkin veriler web tabanlı bir uygulama ile veri tabanında tutulmuştur, enlem, boylam ve alan gibi parametreleri sorgulayan ara yüzü ile mekânsal sorgular gerçekleştiren örnek bir çalışmadır. Bir diğer çalışma ise, mobil cep telefonları için geliştirilen bir mobil uygulamadır. Taşkın ve ark.[18], tarafından Sivas ili için hazırlanan Android işletim sistemine sahip akıllı mobil telefonlar için geliştirdikleri kent rehberi çalışmasıdır. Sivas İline ilk defa gelen bir kişi tarafından kullanılması düşünülerek tasarlanan ve açık kaynak kodlu olarak hazırlanan çalışmadır. Çalışma kapsamında, kullanıcının bulunduğu konumdan, istenilen bir diğer konuma en kısa ağ analizi ile nasıl gidilebileceği gösterilmiştir. Uygulamanın, üniversiteyi ilk defa kazanan öğrenci ve aileleri için çok yararlı olacağı öngörülmüştür.

Literatürde, el terminalleri için paket program geliştiren çalışmalarda mevcuttur $[19,14,15]$. Yağlı ve ark. [19], tarafından HAVELSAN A.Ş. için geliştirilen DOOB Tactical adlı bir komuta kontrol sistemidir. Sistem, dış mekânda kullanılabilecek, telsiz bağlantılı, yüksek güvenlikli, CBS yazılımı içeren, veri toplama, yardım talebi gerçekleştirme özelliklerine sahip bir yapıda olduğu belirtilmektedir.

Ancak, literatür kapsamında; açık kaynak kodlu, farklı mobil cihazlar ve el terminallerinin web tabanlı bir uygulama örneği ile test edildiği bir çalışma ile karşılaşılmamıştır. Böylece, el terminalleri için geliştirilen çalışmalar kapalı kaynak kodlu-ücretli derleyici ortamında geliştirilerek el terminallerine yüklenmiştir [15]. Diğer taraftan mobil uygulamaların geliştirildiği çalışmaların mobil cihazlar için kullanışlı olduğu kadar belli bir süreden sonra işletim sistemine yük getirdiği, hatta bazı mobil cihazlar tarafindan açılamadığ bilinmektedir [22].

Bu çalışma kapsamında, günümüze kadar gerçekleştirilen çalışmalara karşın, web tabanlı farklı üç mobil cihazda test edilecek olan bir mekânsal veri toplama ara yüz geliştirme uygulaması gerçekleştirilecek ve bulgular ile performans değerlendirmesi ortaya konacaktır.

\section{MATERYAL VE METOD (MATERIAL AND METHOD)}

CBS, sahip olduğu çok katmanlı veri yapısı ve farklı formatta veriyi barındırma imkânı birçok mekânsal projenin temelini oluşturmaktadır. CBS' nin veri temini boyutu hem çok zahmetli hem de çok maliyetli bir süreçtir. $\mathrm{Bu}$ bağlamda gerçekleştirilecek çalışma kapsamında, veri teminini kolay, erişilebilir, eş zamanlı ve ücretsiz-açık kaynak kodlu yazılımlarla gerçekleştirmek bu çalışmanın ana hedefidir. Bu hedef doğrultusunda, bu bölümde, sistem analizi, sistem mimarisi ve sistemin gerçekleştirilmesi aşamaları anlatılacaktır. 


\subsection{Sistem Analizi}

Sistem kavramı, karşımıza bazen bir kurum bazense bir problem olarak çıkabilmektedir. Ackoffa göre sistem, "aralarında ilişki bulunan, belirli bir hedefe ulaşmak için, birbirleriyle karşıllklı etkileşme durumu olan elemanlar topluluğudur." [23]. Birbirine bağımlı iki veya daha fazla parçadan oluşan, çalışma ve özellikleri yönüyle belirli bir sınırı olan örgütlenmiş ve ayrılmaz bir bütündür. Aynı zamanda dış çevre ile ilişkisi olan cisim veya varlıkların bileşkesidir [24, 25].

Çalışma kapsamında, kullanıcı için kolay, erişilebilir, açık kaynak kodlu yazılımlarla geliştirilmiş bir alternatif web tabanlı mobil ara yüz tasarlanması ve test edilmesi amaçlanmaktadır. Bu anlamda, işlemlerin genel bir yol haritasını ifade etmesi açısından. Bir akış diyagramı Şekil 3' te verilmektedir.

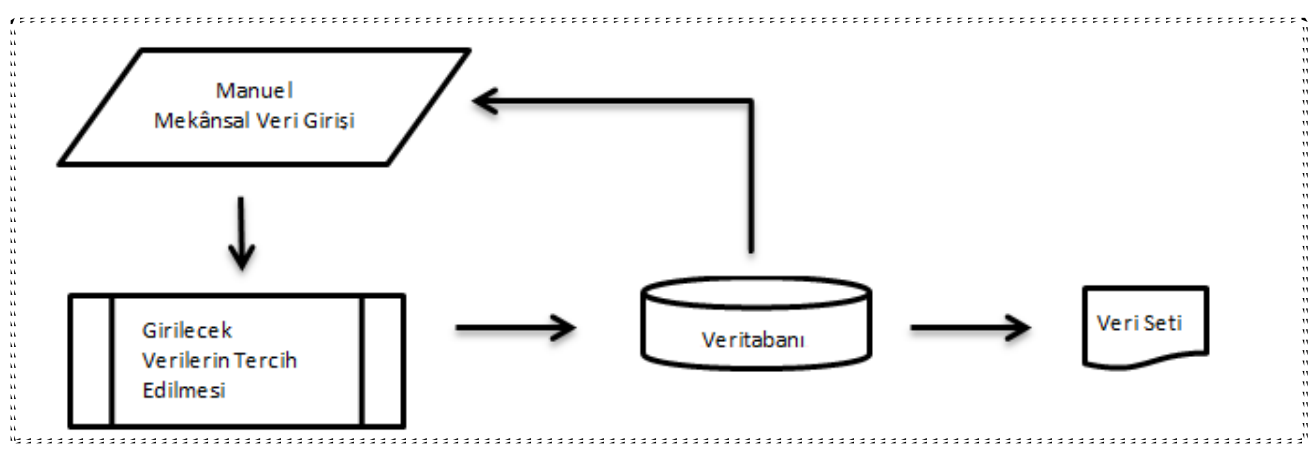

Şekil 3. Akış diyagramı

$\mathrm{Bu}$ diyagrama göre, sahada çalışan mobil kullanıcı, web ortamda projenin alan adını yazarak manuel mekânsal veri girişi için işleme başlayacaktır. Daha sonra, web sayfada oluşturulan form üzerinden girmek istediği verileri tercih edecek ve verilerini girecektir. Son olarak verileri veritabanına gönderecektir. Proje yöneticisi/kurum müdürü/saha amiri, verileri ister mobil mekânsal veri girişi ekranından sorgulayabilecek isterse, veri seti olarak veri tabanından masaüstü CBS yazılımına çekebilecektir.

$\mathrm{Bu}$ işlem adımlarının hayata geçirilebilmesi için sistem mimarisi adımına geçilmiştir.

\subsection{Sistem Mimarisi}

Sistem mimarisi veya çoklu sistemlerin mimarisi olarak adlandırılan; sistemin yapısını, işlevlerini ve biçimselliğini belirleyen kavramsal modeldir [26]. Bir sistem mimarisi sistemin mantıksallarını destekleyecek şekilde organize edilen, karşılıklı ilişkileri standart bir temsilidir. Bu çalışma kapsamında, ara yüz geliştirilmesi ve veri toplanabilmesi için Şekil 4'te ki bir sistem mimarisi tasarlanmıştır.

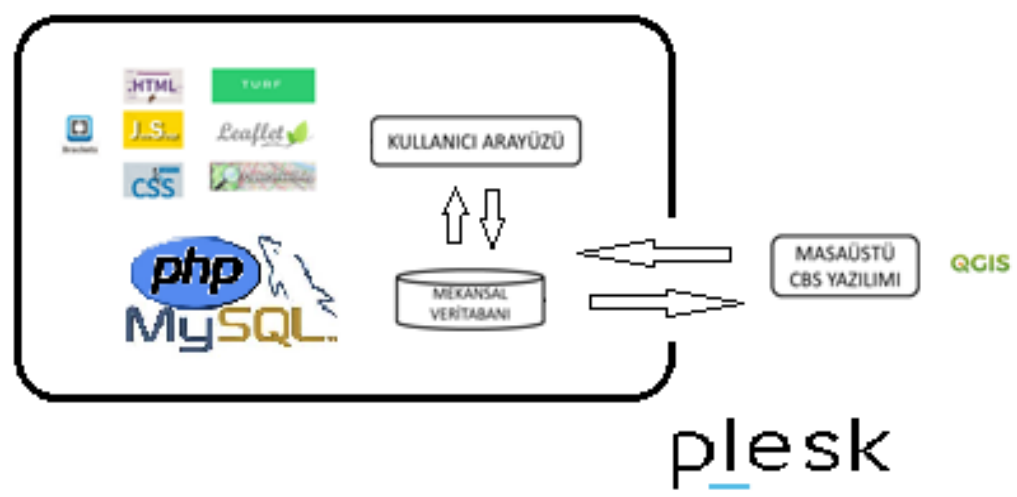

Şekil 4. Sistem mimarisi

Şekle göre; kullanıcı ara yüz açık kaynak kodlu Brackets derleyicisi ortamında, web programlama dillerinden Html, Js, Css ile kodlanacaktır. Harita altlı̆̆ Leaflet ve Open Street Map Java Script 
kütüphaneleri ile desteklenecektir. Mekansal analiz yeteneği Turf.Js kütüphanesi ile kazandırılacaktır. Ayrıca, MySQL veri tabanı ile bağlantı, Php programlama dili ile sağlanacaktır. Jquery ve ajax kütüphaneleri desteği ile web ekranda yenilemeye ihtiyaç duyulmadan veri sorgulaması imkânı sağlanacaktır. Sunucu olarak Plesk sunucusu uygulamanın test edilebilmesi için yerel bir firmadan temin edilmiştir. Verilerin gösterimi için masaüstü CBS yazılımı olarak QGIS kullanılacaktır.

\subsection{Sistemin Gerçekleştirilmesi}

Uygulama açık kaynak kodlu yazılımların kullanılması ile gerçekleştirilmiştir. Kullanıcı ara yüzün geliştirilmesi için Brackets web derleyicisinin kurulumu ile Html, Js ve Css web programlama dilleri kullanılarak arayüz geliştirilmiştir. Ara yüz içerisinde haritaların kullanılabilmesi için Leaflet ve Open Street Map kütüphanesi kullanılmıştır. Ayrıca yakınlık ve tampon analizi yeteneği kazandırabilmek için Turf.Js kütüphanesi kullanılmıştır. Mekânsal veri tabanı olarak MySQL tercih edilmiştir. Plesk sunucusu içerisine kullanıcı arayüz aktarılmış ve MySQL veri tabanı için gerekli tanımlıyıcı ayarlar phpMyAdmin arayüzü ile sağlanmıştır. Proje yönetici/saha amiri tarafından veri girişlerinin takibi ve kontrolünü sağlayabilmesi için MySQL veri tabanı ile masaüstü CBS yazılımı olan QGIS ile entegrasyonu sağlanmıştır. Ayrıca mobil ara yüzden giriş yaparak sorgu ikonu ile veri girişlerini kontrol edebilecektir. Uygulama çalışmasının işlem adımları Şekil 5 'te gösterilmiştir.

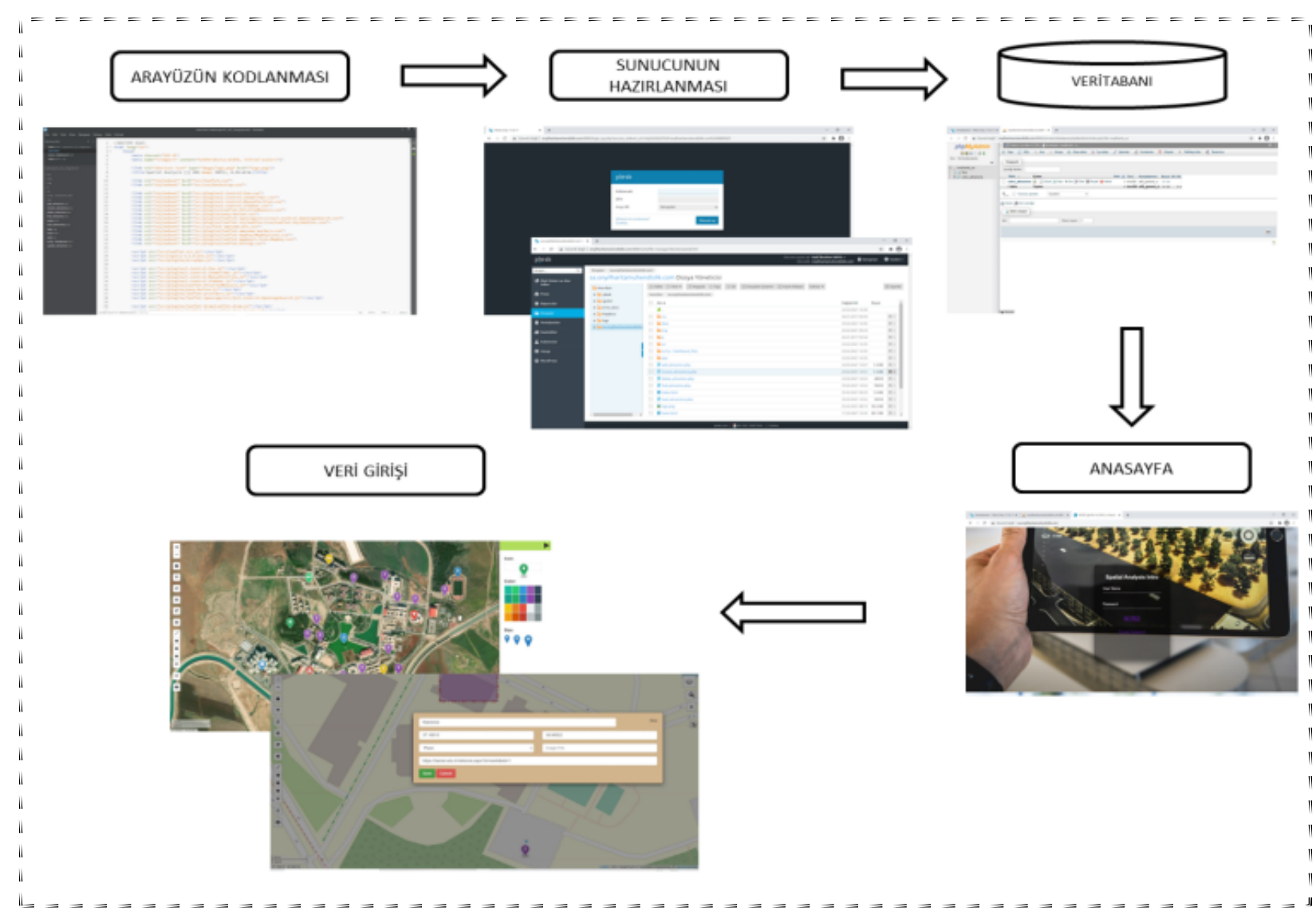

Şekil 5. Sistemin gerçekleşme adımları

Uygulamanın sunucuya aktarılması işlemi ara yüz ve veri tabanının hazırlanmasından sonra, mobil cihazlarda test edilmesi aşamasına geçilmiştir. Bu adımda, üç farklı mobil cihazdan web uygulamaya bağlantı kurularak, mobil cihazların veri giriş, veri sorgulama performansları test edilmiştir. Şekil 6'da mobil cihazlar, uygulamaya giriş ve veri tabanına veri girişi ekran görüntüleri gösterilmektedir. 


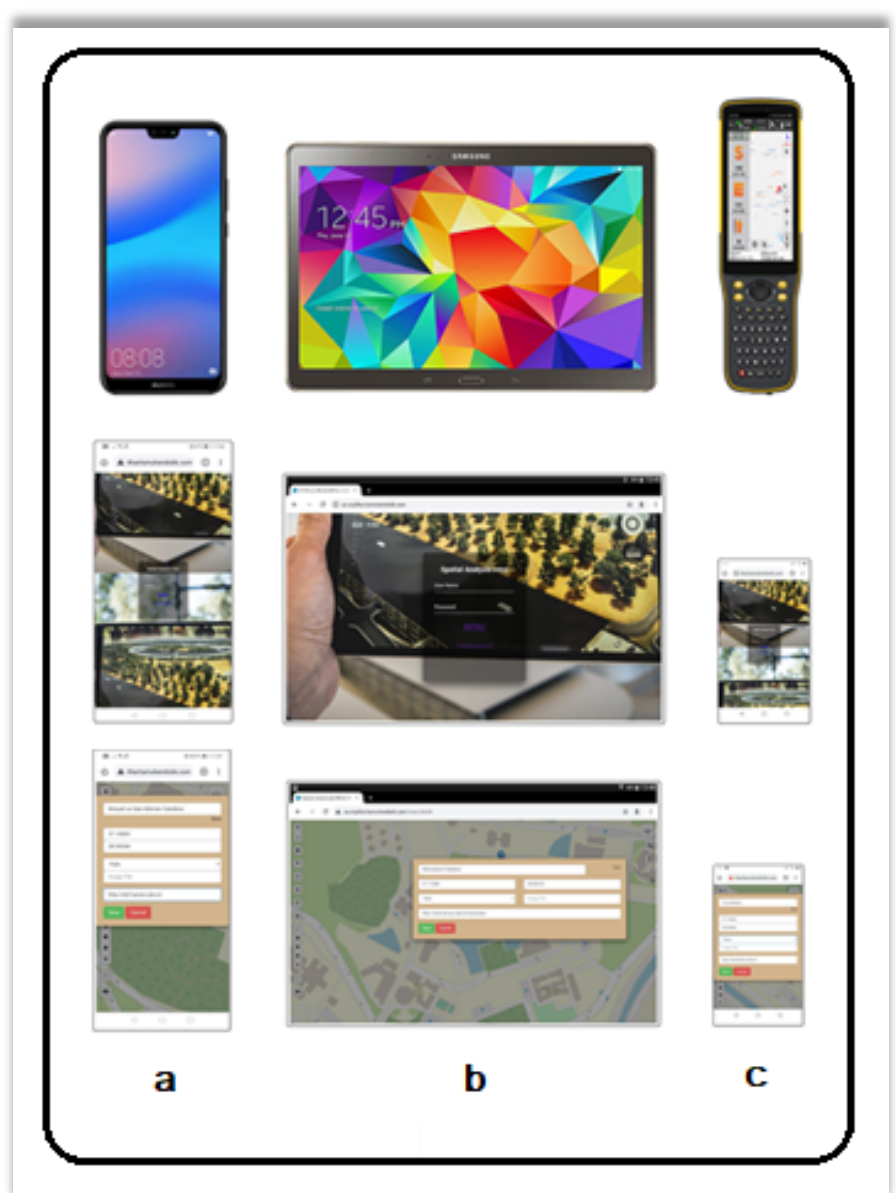

Şekil 6. Mobil cihazlar, anasayfa ve veri girişi (a. Huawei Cep Telefonu, b. Samsung Tablet, c. e-Survey GNSS El terminali)

Uygulama kapsamında veri giriş işleminin gerçekleştirildiği görüntü Şekil 7' de gösterilmektedir.

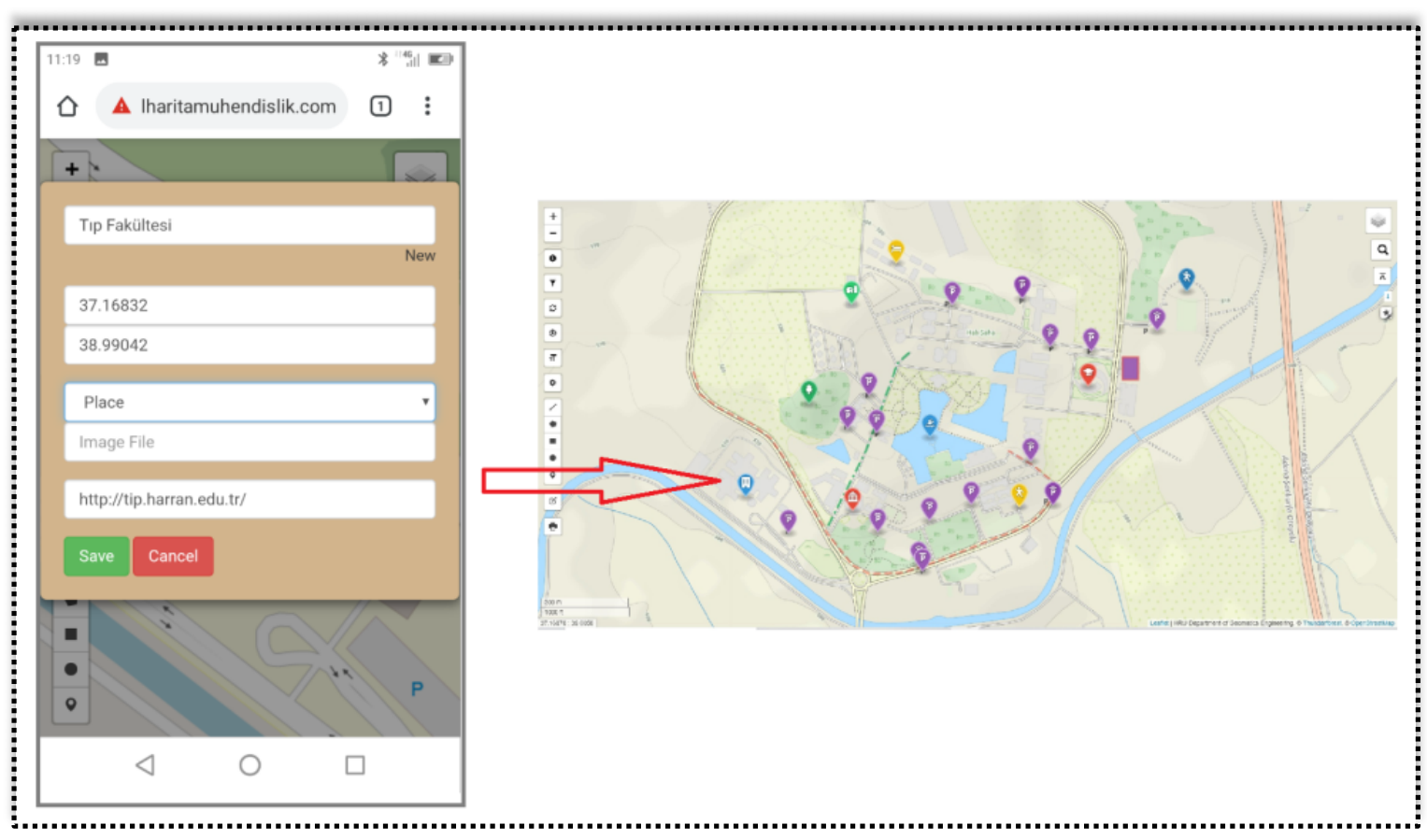

Şekil 7. Veri giriş işlemi 
Son olarak veri tabanına gönderilen verilerin, masaüstü CBS yazılımı QGIS' te görüntülenmesi ve sorgulanması Şekil 8'de gösterilmektedir.

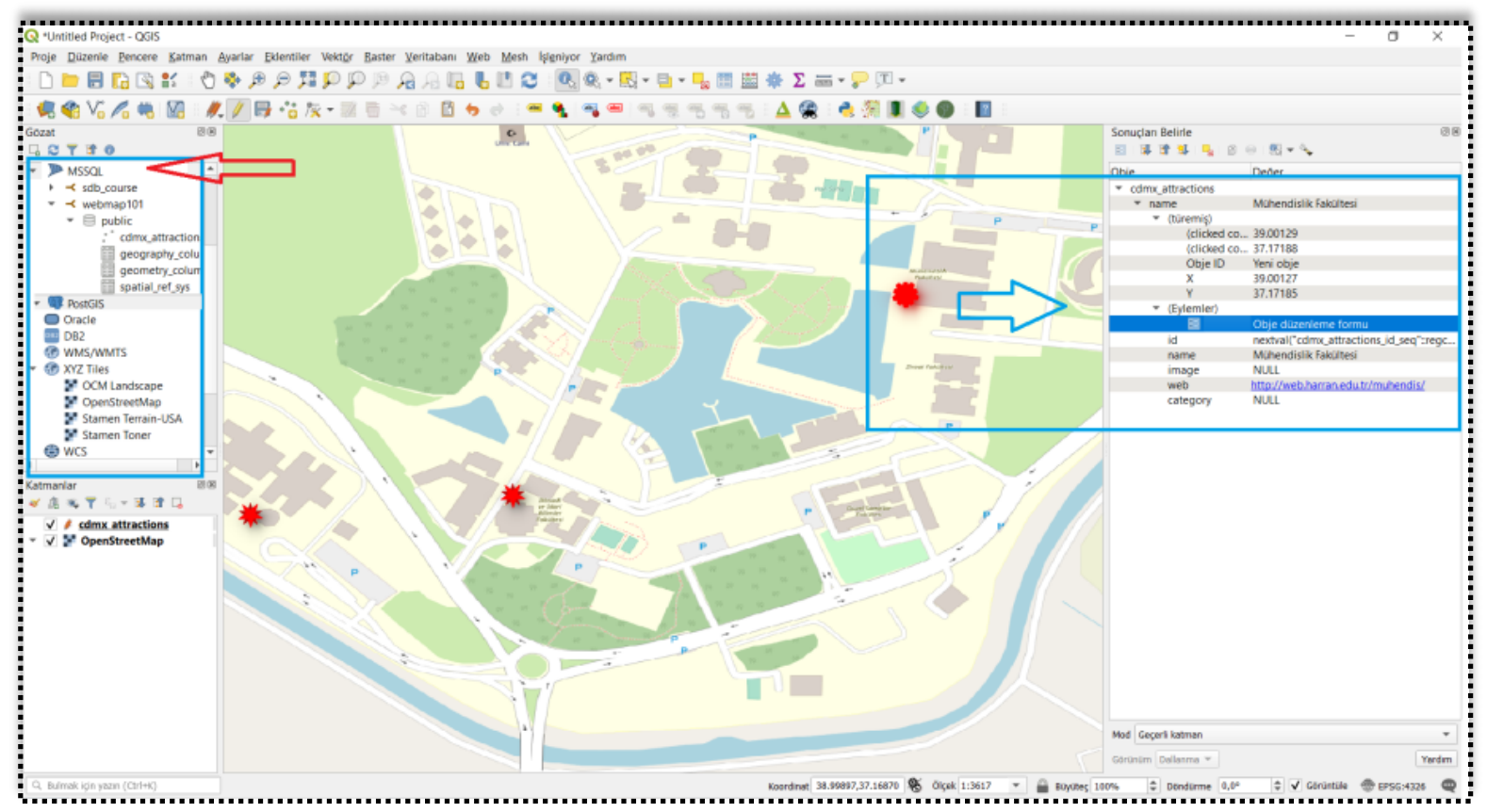

Şekil 8. QGIS ortamında verilerin görüntülenmesi

\section{BULGULAR VE TARTIŞMA (FINDINGS AND DISCUSSION)}

Çalışma kapsamında, açık kaynak kodlu yazılımlarla alternatif web tabanlı bir mobil ara yüz geliştirilmiştir. Üç farklı mobil cihazda test edilen uygulamaya ait bulgular aşağıdadır.

- Kolay, erişilebilir ve eş zamanlıdır. Diğer taraftan, kapalı kaynak kodlu yazılımlar ücretli, lisanslı ve lisans ölçeğinde kullanımı sınırlıdır.

$\mathrm{Bu}$ yeteneği ile web tabanlı bir uygulamada beklenen en önemli özelliği sağlamaktadır. Ayrıca, mobil uygulamaların mobil cihazlara verdiği ağırlaşma problemini yaratmamaktadır.

- Açık kaynak kodlu yazılımlar kullanılmıştır.

Ücretsiz, özgür, kamu lisansına sahip bu yazılımların kullanılması çalışmayı ayrıca cazip hale getirmektedir. Kamu ve özel kurumlar için önemli bir bütçeye sahip olan yazılımların bu yönde kullanılmasına örnek kabul edilebilir.

- Mekânsal verilerin toplanmasında farklı mobil cihazların kullanılması olanağı sağlamıştır.

Projelerde önemli paya sahip olan veri toplama işlemini, aynı anda, farklı mobil cihazlar ile sağlaması ve aynı anda çalışabilme yeteneği ile sürdürülebilir bir uygulamadır.

- Veri tabanında toplanan verilerin, anlık olarak masaüstü CBS yazılımlarında ve aynı web ara yüz de; görüntülenme, sorgu ve analiz imkânı sağlamaktadır. Kapalı kaynak kod çalışmalarda bu imkan ne kadar sağlansa da, lisans sayısı ve kullanıcı kısıtlaması bulunmaktadır.

$\mathrm{Bu}$ yönü ile ofis ekiplerinin eş zamanlı, koordineli çalışmasına ayrıca proje yöneticisi/birim amirinin sahada ya da ofiste veri toplama işleminin son durumunu anlık olarak veri görüntüleme, sorgu ve analiz işlemi sağlayabilmektedir. Veri tabanı ile kapalı kaynak kodlu masasütü CBS yazılımlarla (ArcGIS, NetCAD, MapInfo vb.) da bağlanıp veri çekebilmektedir. 


\section{SONUÇ (CONCLUSION)}

CBS, günümüzün olmazsa olmazları arasına girmiştir. Sahip olduğu çoklu katman yapısı ve farklı tür ve formatta veriyi barındırma özellikleri ile her geçen gün çekici bir hal almaktadır. CBS' nin web ve mobil uygulamaları günümüz şartlarında ve gelecekte ortaya çıkacak olan nesnelerin interneti (IoT), 5G internet teknolojisi ile daha birçok uygulaması bilinmeyen alanlarda, yapay zekâ (AI) ile bütünleşerek, mekânsal zekânın en güçlü temsilcileri arasına gireceğine inanılmaktadır. Bütün bu güçlü yönler düşünüldüğünde CBS' nin yakın gelecekte hayatımızın temel taşı olacağı yadsınamaz bir gerçektir.

Yazılımın hem kamu hem de özel sektörde bilgisayar teknolojileri ile her geçen gün kullanımı daha da artmaktadır. Gelişmiş ülkelerin açık kaynak kodlu yazılımlara yönelerek, hem maliyeti düşürmek hem de siber güvenlik açıklarını azaltmak yönündeki tercihi anlaşılırdır.

CBS' nin beş temel bileşeninden biri olan veri; proje bütçeleri içerisinde en fazla paya sahip kısmıdır. Bu yönüyle, verinin temini, depolanması, sorgu ve analizi çok önem taşımaktadır. Veri biliminin, büyüleyici, baş döndürücü hızda geliştiği dünyamızda, verinin temini; verinin görselleştirilmesi için dayanak oluşturmaktadır. Bu bağlamda gerçekleştirilen uygulama çalışması, diğer kapalı kaynak uygulamalara göre saha verilerinin farklı mobil cihazlardan zamandan ve mekândan bağımsız bir şekilde toplanması yönüyle ayrilmaktadır.

Gerçekleştirilen bu çalışma kapsamında, açık kaynak kodlu yazılımlarla alternatif bir web tabanlı mobil mekânsal veri toplama ara yüzü geliştirilmiştir. Ara yüzün farklı üç mobil cihazda kullanımı test edilmiştir. Test sonuçlarına göre, ara yüzün kullanışlı ve hafif olduğu gözlemlenmiştir. Ayrıca anlık olarak veri toplaması ve paylaşımı sağlaması yönüyle de caziptir. Böylelikle birçok kurum ve kuruluş tarafından kullanımı mümkündür.

Uygulamanın sahadan veri toplama projelerinde kullanılabileceği düşünülmektedir. Bunlar arasında afet sonras1 "hasar tespit ekipleri", belediyelerin fen işleri kontrol mühendislerinin "projelerin anlık durum analizi" için, sağlık personellerinin "anlık hasta durum analizi" gibi uygulamalarda kullanılabileceği öngörülmektedir. Ayrıca, 5G internet teknolojisi ile birlikte, teknik altyap1 nesnelerinin tespitinde, nesnelerinin interneti ile birlikte kullanılabileceği öngörülmektedir.

Açık kaynak kodlu yazılımlar her ne kadar ücretsiz ve kamu lisansı ile ulaşılabilir olsa da, olumsuz yönlerinin olmadığını iddia etmek yersiz olacaktır. Öğrenme aşamasında materyal bulma ve erişme imkânı günümüzde halen kısıtlıdır. Ayrıca, bir kurum tarafından bilgi ve teknoloji güvencesi sağlanmamaktadır. Kullanıcı kurum ve kişiler tarafından arka planda olabilecek durumlar denetlenmelidir. Böylece meydana gelebilecek veri kaybı ve siber problemlerin takibi sağlanmış olacaktır.

Kapalı kaynak kod yazılımların maliyeti, ulaşılabilirliği, ağır masaüstü, web ve mobil paket yazılımlarına karşın, açık kaynak kodlu yazılımlar her geçen gün önemi artmaktadır.

\section{TEŞEKKÜR (ACKNOWLEDGMENTS)}

Çalışmamızda e-Survey GNSS El terminali ve Plesk sunucu temini konusunda desteğini esirgemeyen yerel bir firma olan ONYIL Harita Mühendislik Gayrimenkul Yazılım ve Proje Danışmanlık firmasına çok teşekkür ederiz.

\section{KAYNAKLAR (REFERENCES)}

[1] A. K. Şahinsoy, Açık Kaynak Kodlu CBS Yazılımlarının İmar Planı Verilerinin Yönetilmesinde Kullanımı İstanbul Örneği, İstanbul Teknik Üniversitesi, Fen Bilimleri Enstitüsü, Geomatik Mühendisliği Bölümü, 2011.

[2]Todo,https://www.beyaz.net/tr/guvenlik/makaleler/acik_kaynak_kodlu_yazilimlar_goc_tercihleri.html adresinden, 02.03.2021 tarihinde alındı, 2018. 
[3] Db-Engines Ranking, https://db-engines.com/en/ranking_trend adresinden, 02.03.2021 tarihinde alınd1, 2021.

[4] B. Beyhan, B. Belge, F. Zorlu, Özgür ve Açık Kaynak Kodlu Masaüstü CBS Yazılımları Üzerine: Karşılaştırmalı ve Sistemli Bir Değerlendirme, Harita Dergisi, 143 (2010), 45-61.

[5] G. Filiz, D. Maktav, K. Kalkan, O. Özer, Mobil Platformlar Üzerinden Gerçek Zamanlı Ekip Takip Sistemi. TOBB Coğrafi Bilgi Sistemleri Kongresi, Ankara, 2013.

[6] A. Memduhoğlu, A. M. Başaraner, Y. S. Şengün, Açık kaynaklı yazılımlar ile OGC web servisleri üzerinden görerek uçuş bilgilerinin kartografik sunumu, Harita Dergisi, 82:156 (2016), 41-55.

[7] B. Kalkan, K. Kalkan, Lojistik Yönetimde Coğrafi Bilgi Sistemi Uygulamaları, 6. Uzaktan AlgılamaCBS Sempozyumu (UZAL-CBS 2016), 5-7 Ekim 2016, Adana, 2016.

[8] Y. Önder, T. Kavzoğlu, Açık Kaynak Kodlu CBS Yazılımları ile Trafik Kaza Yoğunluk Analizleri: İstanbul Örneği . Türkiye Coğrafi Bilgi Sistemleri Dergisi , 2:1 (2020) , 1-9 . Retrieved from https://dergipark.org.tr/tr/pub/tucbis/issue/52936/650974.

[9] H. Ledoux, F. Biljecki, B. Dukai, K. Kumar, R. Peters, J. Stoter, T. Commandeur, 3dfier: automatic reconstruction of 3D city models. Journal of Open Source Software, 6:57 (2021), 2866.

[10] C. Yalçın, L. Sabah, Açık Kaynak Kodlu CBS ve Analitik Hiyerarşi Proses (AHP) Yöntemi Kullanılarak Edirne Sanayi İşletmelerinin Deprem Tehlike Analizi . Düzce Üniversitesi Bilim ve Teknoloji Dergisi , 5:2 (2017) , 524-537, Retrieved from https://dergipark.org.tr/en/pub/dubited/issue/30665/310511?publisher=duzce;.

[11] C. Apaydın, S. Abdikan, Fındık Bahçelerinin Sentinel-2 Verileri Kullanılarak Piksel Tabanlı Sinıflandırma Yöntemleriyle Belirlenmesi . Geomatik , 6:2(2021) , 107-114 . DOI: 10.29128/geomatik.705988,

[12] We Are Social and Hootsuite (W\&H), https://dijilopedi.com/2020-dunya internet-sosyal-medya-vemobil-kullanim-istatistikleri/ adresinden 03.03.2021 tarihinde alınd1, 2020.

[13] H. İ. Zeybek, H. Çam, Mobil coğrafi bilgi sistemlerinin kullanımını etkileyen faktörlerin teknoloji kabul modeli çerçevesinde incelenmesi. Gümüşhane Üniversitesi Sosyal Bilimler Enstitüsü Elektronik Dergisi, 11(Ek-2020), 14-26.

[14] A. Dinçer, Design and implementation of a search tool for roads on pocket PCs for mobile GIS, METU Master of Science Thesis, Ankara, 2006.

[15] A. Dinçyılmaz, Altyapı Bilgi Sistemlerinde Mobil CBS Uygulamaları İSKİ Altyapı Bilgi Sistemi (İSKABİS) Örneği, İTÜ Fen Bilimleri Ensititüsü Yüksek Lisans Tezi, İstanbul, 2009.

[16] E. Güler, Developing A Web Based Mobile GIS Application for Soil Mapping Studies, Konya Technical University, PhD Thesis, Konya, Turkey, 2020.

[17] U. Çağatay, H. Yıldız, Belediyelerin Çevre Yönetimi Üzerine Açık Kaynak Kodlu Bir Kent Bilgi Sistemi Uygulamas1, Dumlupinar University Journal of Social Science/Dumlupınar Üniversitesi Sosyal Bilimler Dergisi, 34 (2012).

[18] T. Taşkın, A. C. Birdal, T. Türk, Android Ortamında Kent Rehberi Geliştirilmesi: Sivas İli Örneği. TMMOB Harita ve Kadstro Mühendisleri Odas1. 16. Türkiye Harita Bilimsel ve Teknik Kurultayı. 3-6 Mayıs 2017. Ankara, 2017. 
[19] T. Yomralığlu, F. Döner, Mobil GIS: Gezici Coğrafi Bilgi Sistemleri ve Uygulamaları . Jeodezi ve Jeoinformasyon Dergisi , 93 (2005) , 30-37 . Retrieved from https://dergipark.org.tr/tr/pub/hkmojjd/issue/53186/705646.

[20] Ö. Akçay, An Ontological Approach to Relevant Visualisation in Mobile GIS (Doctoral dissertation), 2008.

[21] T.Yağlı, H. D Erten, R. Yamaç, T. Yılmaz, Mobil Kullanıma Yönelik Taktik Komuta Kontrol Sistemi Yazılımı Geliştirilmesi, HAVELSAN, 2015.

[22] G. Ekren, M. Kesim, Mobil iletişim teknolojilerindeki gelişmeler ve mobil öğrenme . Açıköğretim Uygulamaları ve Araştırmaları Dergisi , 2:1 (2016) , 36-51 . Retrieved from https://dergipark.org.tr/tr/pub/auad/issue/34011/376511.

[23] R. Ackoff, Systems, Organizations and Interdisciplinary Research, 2012.

[24] Y.K. Kaya, Eğitim Yönetimi Kuram ve Türkiye' deki Uygulama.Türkiye Orta Doğu Amme İdaresi Enstitüsü.Sayfa 81, 1979.

[25] Wikipedia, Wikipedia Özgür Ansiklopedisi. https://tr.wikipedia.org/wiki/Sistem\#cite_note-3 adresinden 04.03.2021 tarihinde alınmıştır, 2021.

[26] O. H. Yüreğir, System analysis and design in informatics. ISBN:975-85-61-05-7, 2001. 